\title{
Late Lumen Loss Measurement
}

National Cancer Institute

\section{Source}

National Cancer Institute. Late Lumen Loss Measurement. NCI Thesaurus. Code

C116146.

The difference between the mean minimum lumen diameter (MLD) assessed

immediately after an index procedure and the MLD assessed at follow-up angiography. 